\title{
28 Research Square \\ Factors influencing early initiation of breastfeeding among mothers in Rajshahi district, Bangladesh
}

\author{
Ummay Ayesha
}

University of Rajshahi

Abu Sayed Md. Al Mamun

University of Rajshahi

Md. Nurul Islam

University of Rajshahi

Md. Ripter Hossain

University of Rajshahi

Samme Amena Tasmia

University of Rajshahi

Md. Golam Hossain ( $\sim$ hossain95@yahoo.com )

University of Rajshahi https://orcid.org/0000-0002-3822-5489

\section{Research article}

Keywords: Initial breastfeeding, socio-economic factors, demographic factors, logistic regression, Rajshahi

Posted Date: September 16th, 2020

DOI: https://doi.org/10.21203/rs.3.rs-34757/v2

License: (c) (i) This work is licensed under a Creative Commons Attribution 4.0 International License.

Read Full License 


\section{Abstract}

Background: Early initiation of breastfeeding (EIBF) is referred to as providing breast milk to the newborn within one hour of birth. ElBF ensures that the infant receives the colostrum containing highly protective antibodies. This study aimed to identify the influential factors of EIBF among mothers in Rajshahi district, Bangladesh.

Methods: The data was collected from mothers living in Rajshahi district who had at least one child aged 6-24 months. This study was conducted from January to March, 2019. The ElBF was measured by a principal question, "Did you provide your breast milk to your infant within one hour after delivery?" Frequency distribution and Chi-square test and multivariable binary logistic regression model were utilized in this study for getting prevalence and influential factors of EIBF respectively.

Results: This study revealed that the prevalence of ElBF among mothers in Rajshahi district was 88.4\%. Multivariable logistic model provided eight influential factors of EIBF: (i) place of delivery, (ii) family monthly income, (iii) husbands' education level, (iv) mothers' nutritional status, (v) mothers' age, (vi) husbands' occupation, (vii) getting pregnancy with planning, and (viii) mothers taking advice regarding the benefit of breastfeeding during their pregnancy.

Conclusions: This study identified several modifiable influential factors of EIBF. The customs, culture and other characteristics are almost the same across the country. These factors could be considered to increase the rate of EIBF among mothers in Bangladesh.

\section{Background}

Breastfeeding is considered one of the most important factors for the growth and development of infants. World Health Organization defined breastfeeding as the normal way of providing young infants with the nutrients they need for healthy growth and development. Breast milk is the best source of nutrition for the newborn which is uniquely tailored to meet all the nutritional needs of human babies for the first six months of life [1]. The nutrients of breast milk possess remarkable immunological and antiinflammatory properties that protect both mothers and children against various infections and diseases [2-4]. Early initiation of breastfeeding or timely initiation of breastfeeding is referred to as providing the breast milk to the newborn infant within one hour of birth which ensures that the infant receives the colostrum [5]. Colostrum, the "first milk" produced by the mothers during the first postpartum days, endowed with protective antibodies that inevitably act as the first immunization for the infants, fortify their immune defense system and eventually reduce the mortality rate of the neonates [6]. It contains at least ninety known components including amino acids, minerals and vitamins essential for the growth and development of the newborns [7]. Early initiation of breastfeeding ensures skin-to-skin contact between the mothers and the infants which helps in preventing hypothermia of the new-born baby, establishes the bond between mothers and children, and most importantly boosts the chances of 
increasing exclusive breastfeeding practice [8]. EIBF also shows a significant protective role to mothers by reducing the risk of postpartum hemorrhage which is a leading cause of maternal mortality [9].

The prevalence of EIBF is the measure of children born who were put to the breast within one hour of birth [10]. The effective initial breastfeeding coverage has been estimated to avert $13 \%-15 \%$ of deaths among children under five years of age especially in middle and low earning settings [11]. Some researchers reported that children who received initial breastfeeding were at lower risk of having acute respiratory and gastrointestinal infections compared to children who didn't receive initial breastfeeding [12]. On the other hand, late initiation of breastfeeding increases the risk of morbidity and mortality such as a five-fold increase in the incidence of diarrheal diseases [13]. Infectious diseases and malnutrition due to poor breastfeeding practice are major causes of infant death in developing countries [13-14].

There are a lot of studies pursued with the early initiation of breastfeeding worldwide [15-17]. In Bangladesh, the trend of practicing early initiation of breastfeeding among the lactating mothers has remained mostly unchanged for the last one decade [18]. It is important to sort out the factors that influence the early initiation of breastfeeding to implement strategies and interventions that could speed up the government efforts in improving early initiation of breastfeeding trends among mothers in Bangladesh. More recently, Islam et al. [19] investigated the prevalence and factors associated with early initiation of breastfeeding among Bangladeshi mothers using a nationally representative samples collected by Bangladesh Demographic and Health Survey-2014 (BDHS-2014). BDHS collected data in 2014 , since then 6 years have already passed, and some indicators related to early initiation of breastfeeding could have been changed in Bangladesh. They found the prevalence of EIBF among mothers in Bangladesh was $51 \%$, and they also reported that $89 \%$ of infants are breastfed within one day after delivery [18]. The household wealth quintile, medical facilities and women education level have been increasing in Bangladesh during the last two decades; these factors are directly or indirectly related to EIBF [18]. Bangladesh Government is providing medical facilities for ensuring the antenatal and postnatal care services of mothers in Bangladesh consequently the rate of EIBF and exclusive breastfeeding are increasing [18]. Bangladesh Government is trying to achieve 17 goals under SDGs by 2030. One of the important goals of SGDs is to reduce maternal and under-five child mortality, and EIBF is one of the important factors for reducing maternal and under-five child mortality. It is necessary to determine the current prevalence and associated factors of EIBF among Bangladeshi mothers. Rajshahi district is a part of the northern region of Bangladesh. BDHS-2014 did not find a significantly variation in the rate of EIBF among geographical locations (divisions) in Bangladesh [18]. To the best of our knowledge, no research has been conducted in Rajshahi district regarding this issue.

The objective of this study was to determine the prevalence and associated factors of early initiation of breastfeeding among mothers in Rajshahi district, Bangladesh.

\section{Methods}


Study area and population: Rajshahi district was the target area of the present study. It is one of the oldest districts of Bangladesh that belongs to the Northern region of the country under Rajshahi division. The area of Rajshahi district is $2407.01 \mathrm{sq} \mathrm{km} \mathrm{[20].} \mathrm{A} \mathrm{total} \mathrm{number} \mathrm{of} \mathrm{population} \mathrm{living} \mathrm{in}$ Rajshahi district is $22,868,74$ including $11,844,48$ males and $11,024,26$ females [21]. All mothers who had at least one child (age, 6-24 months) were considered as the study population. For this crosssectional study, data was collected from January to March, 2019.

Sample size determination: The required sample size for this study was estimated using the formula given by Cochran [22]: $\mathrm{n}=\frac{z^{2} p(1-p)}{d^{2}}$, where $\mathrm{n}=$ the required sample size, $\mathrm{p}$ is the proportion of prevalence of early initiation of breastfeeding (here, $p=0.514$ ) and $z=1.96$ at $95 \%$ confidence interval, and $d$ is the margin of error, we considered $d=0.05$. The prevalence of initiation of breastfeeding ( $p$-value) was taken from a previous publication [19]. This formula provided that 384 sample was adequate for our present study. However, 440 samples (15\% extra) were considered for the study for allowing some failure cases.

Sampling: Multistage random sampling was utilized for this study. In the first stage, 2 Upazilas were selected randomly from 9 Upazilas in Rajshahi district. In the second stage, 2 unions were selected from each selected Upazilas randomly. Similarly, 1 ward was selected randomly from 30 wards of Rajshahi City Corporation. In the third and final stage, 80 mothers were selected from each selected union and 120 mothers were selected from the ward randomly. In each stage, a simple random sampling method (by lottery) was used. All necessary information of our respondents was collected from the respective ward councilor's office/union parishad. Before, collecting data, we discussed our research with selected mothers and their husbands/guardians. Unfortunately, 19 selected mothers did not agree to provide their information, finally, 421 mothers' information was analyzed in this study. The written consent had been taken from mothers who agreed to provide their information. A self-administered questionnaire was used for collecting information from selected mothers. The questionnaire was draft and sent to five experts who were researching in health science for taking their opinions/suggestions to improve it. According to experts' comments/suggestion the questionnaire was modified and finalized for data collection. The original questionnaire was in English, and the revised questionnaire was translated into Bangla (mother tongue of Bangladesh), and the Bangla questionnaire was checked by two authors. A pilot survey had been done for observing whether there was any lacking or drawback in the questionnaire. We did not get lacking or drawbacks.

Measurement of anthropometric data: Digital scales and a portable stadiometer was used to measure weight and height of our samples. Measurement of individuals was taken without shoes and wearing light clothes using the techniques of Martin and Saller [23]. Height and weight were measured to the nearest $1 \mathrm{~cm}$ and $0.1 \mathrm{~kg}$, respectively, and body mass index was calculated using the formula, BMI = weight $(\mathrm{kg}) /$ height $(\mathrm{m})^{2}$. Nutritional status was classified into three classes according to the cutoff points of BMl: (i) under nutrition (18.5 kg/m² $<$ BMI), (ii) normal (healthy) $\left(18.5 \leq \mathrm{BMI}<25 \mathrm{~kg} / \mathrm{m}^{2}\right)$ and (iii) over 
nutrition $\left(B M I \geq 25 \mathrm{~kg} / \mathrm{m}^{2}\right)$ [19]. In addition, mothers' age was calculated by the difference between the date of interview and their date of birth, and we considered the nearest higher integer.

Outcome variable: Early initiation of breastfeeding (EIBF) was considered as the outcome variable in this study. It was measured by a question, "Did you provide your breast milk to your infant within one hour after delivered? EIBF was expressed as a dichotomous variable with category one for initiation of breastfeeding within one hour (early initiation) and category 0 for initiation of breastfeeding after one hour (late initiation).

Independent variables: Some socio-economic, demographic and anthropometric factors were considered as independent variables for this study. The variables were selected and coded (Table 1 ) on the basis of previous studies [19,24-25]. All selected variables, their categories with codes are described in Table 1.

Statistical analysis: Frequency distribution (percentage) was used to determine the prevalence of EIBF among mothers in Rajshahi district, Bangladesh. Chi-square tests were conducted to assess the association between independent variables and the EIBF. Binary multiple logistic regression analysis was used to detect the association of socio-economic, demographic, anthropometric and behavioral factors on EIBF among mothers in Rajshahi district. We used the magnitude of the standard error (SE) for detecting the multicollinearity problem among the independent variables, if the magnitude of the SE lies between 0.001 and 0.5 , it is judged that there is no evidence of multicollinearity [26]. A value of $p<0.05$ was considered statistically significant in the analysis. All statistical analyses were performed using SPSS (IBM Version 21).

\section{Results}

A total number of 421 samples were selected from mothers having at least one child (age, 6-24 months) in Rajshahi district, Bangladesh to determine the prevalence and associated factors of early initiation of breastfeeding (EIBF).

We found that $88.40 \%$ of mothers provided their breast milk to their newborns within one hour after delivery (Table 2). Out of the total sample population 421 mothers, $42 \%$ of mothers delivered their child by $\mathrm{C}$-section, and near half of the mothers (47.5\%) delivered their child in public hospitals. More than $68 \%$ of mothers were living in low-income families (below15000 Taka). By education, $47.7 \%$ of mothers were primary or uneducated while $11.2 \%$ had higher education, and $47.5 \%$ of their husbands were primary or uneducated and $14.7 \%$ of got higher education. Out of samples, $47.3 \%$ of mother's age at first birth was below 20 years. More than $67 \%$ were healthy (normal weight) while $25.7 \%$ mothers were undernourished. More than $71 \%$ and $82 \%$ of mothers were living in rural areas and nuclear families respectively. $79.33 \%$ of mothers were $20-29$ years old, $98.57 \%$ of mothers and $55.82 \%$ of their husbands were housewives and farmers respectively. More than half of mothers (55.34\%) had one child, and $50.36 \%$ of children were boys. $83.61 \%$ of mothers got pregnancy with proper planning, and $94.77 \%$ of mothers took advice during pregnancy regarding the benefit of breastfeeding from health providers (Table 2). Chi-square test 
provided that mode of delivery, place of delivery, respondents' and their husbands' education level, respondents' nutritional status, monthly family income, respondents' age at first birth, type of residence, mothers' age, mothers' occupation, their husbands' occupation and taking advice regarding the benefit of breastfeeding during pregnancy were significantly associated factors of initial breastfeeding among Rajshahi mothers (Table 2). These factors were considered as independent variables in multivariable binary logistic regression models.

Table 3 shows the effect of socio-economic and demographic factors on EIBF among mothers in Rajshahi district, Bangladesh. For this purpose we used multivariable binary logistic regression, the standard error (SE) was utilized for checking the multicollinearity problems among the independent variables, SE showed that there was no evidence of this problem except the type of residence due to all rural mothers provided EIFB. This variable could not possible to consider as independent variables in the logistic model. The results of this model were interpreted using p-value, adjusted odds ratio (AOR) with $95 \%$ confidence interval $(\mathrm{Cl})$ for AOR. After adjusting the effect of other variables, the logistic model demonstrated that mothers delivered at private hospitals reduced the EIBF rate by $91 \%$ compared to home delivered mothers ( $A O R=0.090,95 \% \mathrm{Cl}: 0.010-0.794 ; \mathrm{p}<0.05)$. The rate of EIBF was decreased by $90.3 \%$ and $87.0 \%$ among mothers who were living in middle-income families (AOR=0.097, 95\% $\mathrm{Cl}: 0.030$ $-0.315 ; p<0.01)$ and rich families (AOR=0.130, 95\% Cl: 0.039-0.437; $p<0.01)$ compared to mothers living in poor income families respectively. We found that the rate of EIBF was reduced by $83.3 \%$ among higher educated husbands' wives (AOR=0.167, 95\% Cl: $0.035-0.792 ; \mathrm{p}<0.05)$ compared to primary or uneducated husbands' wives. The nutritional status of mothers was an important predictor of initial breastfeeding, and it was observed that the rate EIBF was diminished by $89.2 \%$ and $92.8 \%$ among healthy (normal weight) ( $A O R=0.108,95 \% \mathrm{Cl}: 0.013-0.867 ; p<0.05)$ and over nourished mothers $(A O R=0.072,95 \%$ $\mathrm{Cl}: 0.008-0.692 ; \mathrm{p}<0.05)$ compared to undernourished mothers. It was found that the rate of ElBF was 7.133, 3.069 and 7.385 fold higher among mothers aged $20-24$ years ( $A O R=7.133,95 \% \mathrm{Cl}$ : 2.273-22.381; $p<0.01$ ), 25-29 years [AOR=3.069, 95\% Cl: 1.047-8.997; $p<0.05)$, 30-34 years (AOR=7.385, 95\% Cl: 1.623$33.607 ; p<0.01)$ than mothers aged 35 years and above. Farmers' wives provided their initial breast milk to their infants had 13.568 times ( $A O R=13.568,95 \% \mathrm{Cl}: 5.237-35.154 ; p<0.01$ ) higher than others professional husbands' wives. Mothers who got pregnancy with proper planning had provided EIBF 5.941 fold higher (AOR=5.941, 95\% Cl: 2.237-15.780; $p<0.01$ ) than those who did not do it. Mothers who took advice regarding the benefit of breastfeeding during their pregnancy had 7.502 times (AOR=7.502, 95\% Cl: 2.877-19.559; $p<0.01$ ) higher to provide EIBF than mothers who did not get it. Hosmer and Lemeshow test demonstrated that our selected model was good fitted, and the model can able to explain the variation of outcome variable by $56.60 \%$ (Nagelkerke $\mathrm{R}^{2}$ - value $\left.=0.566\right)$ (Table 3 ).

\section{Discussion}

In the present study, we tried to determine the prevalence of early ignition of breastfeeding (EIBF) and investigate the associated factors of EIBF among mothers living in Rajshahi district, Bangladesh. It was noted that the prevalence of EIBF among mothers was $88.40 \%$. The national survey of Bangladesh 
(BDHS-2014) showed that $51.0 \%$ of neonates were breastfed within one hour after birth (EIBF) and $89 \%$ within one day after delivery, and $55.0 \%$ of infants under the age of 6 months were exclusively breastfed [18]. However, more recently published key indicators of BDHS 2017-2018 showed that $65 \%$ of infants under the age of 6 months were exclusively breastfed (EB) in 2017, a level markedly higher than that found in BDHS-2014 [27]. The prevalence of EIBF is not available in the report of BDHS 2017-2018 [27]. BDHS-2014 found that $98 \%$ of children born during the two years of their survey were breastfed at some point in their life in Bangladesh where breastfeeding was almost universal [18]. The rate of breastfeeding for every stage has been increasing with increase of the medical facilities in Bangladesh. Mothers can easily get advice about the benefit of breastfeeding from health providers and family planning workers. Also, the practice of providing EIBF was increasing with increasing literacy rate among women that enhanced the awareness regarding the benefit of EIBF especially among rural women in Bangladesh [18]. BDHS-2014 conducted their survey about 6 years ago, some indicators such as mother education level, medical facilities, household wealth quintile have continued to increase during the last two decades in Bangladesh which is ultimately helping to increase the rate of EIBF.

The prevalence of EIBF among mothers in Rajshahi district was also higher than south Asian countries like India (21\%) [28], Pakistan (8.5\%) [29], other developing countries like Nigeria (34.7\%) [30], Iran (32.2\%) [31] and South Sudan (48\%) [32]. The rate of EIBF of mothers in Ethiopia was close (83.7\%) to our finding [33].

Mothers who delivered at home were more likely to provide EIBF to their infant than mothers delivered at private hospitals. A Bangladeshi study found that mothers undergoing vaginal delivery were more likely to provide EIBF to their infants than mothers having cesarean delivery [19]. The present finding coincided with a Chinese study [34]. It was noted that mothers living in poor-income families were more interested to provide initial breast milk to their infants than those of middle- and high-income families, and the rate of EIBF was decreasing with increasing family income. The same results had been found in another Bangladeshi study that used BDHS-2014 data [19].

We found that primary or uneducated husbands' wives had more chances to give their initial breast milk to their infants than higher educated husbands' wives. This finding was supported by another study [35]. They also found that the husband's educational level was significantly associated with EIFB.

The nutritional status of mothers was an important predictor of initial breastfeeding, and it was observed that undernourished mothers were more likely to provide their breast milk to their infants than healthy and over nourished mothers. The same results had been found in our nationally representative samples [19]. A similar observation was also mentioned by several studies [36-39, 32-34]. This study found that mothers aged 20-34 years were more likely to provide EIBF to their children than mothers aged 35 years and above. Our result was also supported by a global survey [40-41]. Again, in this study, it was found that husband's occupation is an important factor for EIBF, i.e. farmers' wives had a higher chance to give EIBF to their children than other professional husbands' wives. Our result was also in line with another study in India [42], but disagreed with a study in Sudan [43]. 
In this study, we have found that place of delivery, family income, husbands' education level and mothers' nutritional status are important factors for providing initial breast milk to newborn among mothers in Rajshahi district. These four factors are very much related to each other in developing countries like Bangladesh. Most of the home delivery mothers are living in poor families. In Bangladesh, the wife is dominated by her husband, and most of the females are dependent on their husbands' income, and income is dependent on education level. Usually, uneducated or primary educated husbands are farmers or day labors living in rural or slum areas, their income is not sufficient to maintain their family, and they cannot provide sufficient food to their family members, consequently, they suffer from under nutrition. Mothers living in poor families cannot go to hospitals/clinics for delivery, and most of them deliver at home in the presence their close relatives without proper nursing. Traditional customs and culture in the society of Bangladesh are that, after delivery, the mother immediately provides her breast milk to the newborn. It is true especially for most of the mothers having vaginal delivery. It is also mentionable that all home deliveries are vaginal. On the other hand, mothers living in middle or rich families usually deliver at hospitals/clinics under proper nursing. But now a days most of the hospital/clinic deliveries are caesarian, and after the delivery, mothers stay at the operation theatre for more than one hour, and cannot provide breast milk to their infant in time (within one hour of delivery). Mothers living in poor families are more likely to provide breast milk to their newborn than those living in rich families. A similar result was found in another Bangladeshi study [19]. Healthy and over nourished mothers usually live in rich families, and most of them underwent caesarean section. It might create a higher risk of cephalo-pelvic disproportion and relatively poor progress due to maternal fatigue [44]. This is one of the most important reasons for the differences seen in the practice of EIBF between undernourished and over nourished mothers. Healthy and over nourished mothers should be the focus of education on the potential benefits of EIBF. We found that mothers getting pregnant with proper planning and taking advice regarding the benefit of EIBF were more likely to provide EIBF than their counterparts. Family planning workers closely working with pregnant mothers and healthcare providers can play a good role to increase the rate of EIBF and exclusive breastfeeding in Bangladesh.

Strength and limitations of this study: Perhaps, this was the first time we attempted to investigate the early initiation of breastfeeding and its influential factors among mothers in Rajshahi district, Bangladesh. We considered two new factors; (i) getting pregnant with planning and (ii) mothers taking advice regarding the benefit of breastfeeding during their pregnancy, which were not considered in our national survey. However, there are several limitations of our present project. Firstly, in this study, we considered only Rajshahi district as our study area which is a small part of Bangladesh. Secondly, we used a quantitative study which can determine only risk factors but cannot do research in-depth. For complete study, mixed research (qualitative and quantitative) is important. Thirdly, we selected some socio-economic, demographic, anthropometric and behavioral factors as independent variables but other important factors were not considered in this study. Fourth, we did not consider the pre-lacteal feeding for calculating the prevalence of EIBF, and it would be better to ask mothers about providing EIBF immediately after delivery for getting accurate information; but we asked after 6-24 months of delivery. 
On the basis of our limitations, we may proclaim that further researches are required on breastfeeding among Bangladeshi mothers.

\section{Conclusions}

In this study, we considered 421 mothers living in Rajshahi district, Bangladesh having at least one child aged 6-24 months as samples to determine of EIBF and its related factors. Our selected statistical models provided that the rate of EIBF among mothers in Rajshahi district was $88.40 \%$; the predictors of EIBF were: place of delivery, family monthly income, husbands' education level and occupation, mothers' nutritional status, mothers' age, getting pregnant with proper planning and taking advice regarding the benefit of ElBF. These findings would help the health authorities of Bangladesh government and nongovernment organizations working with mothers and children health and nutrition for improving their strategies to increase the rate of EIBF.

\section{Abbreviations}

AOR- Adjusted Odds Ratio; BDHS- Bangladesh Demographic and Health Survey; EB- Exclusively breastfed; EIBF-Early initiation of breastfeeding; IBM- International Business Machines; SE- Standard error; SPSSStatistical Package for the Social Sciences.

\section{Declarations}

Ethics approval and consent to participate: Ethics statement: We followed all rules and regulations of Institute of Biological Science (IBSC), University of Rajshahi, Bangladesh, and IBSC approved this study also they provided an ethical clearance letter (Memo No: 69/320/IAMEBBC/IBSC). Written consent was taken from each participant, the consent was taken from the husband or guardian for participants under 16 years old.

Consent for publication: Not applicable to this study.

Availability of data and materials: The study was based on the primary data. The data will be provided when necessary.

Competing interests: The authors declare that they have no competing interests.

Funding: The authors have no support or funding to report.

Authors' contributions: UA and GH created the concept; ASMAM, MNI, MRH and GH created the design of the study; ASMAM and SAT performed the statistical analysis; UA, ASMA, MIN, RH and GH drafted the manuscript. GH, ASMAM, and SAT made revision of the manuscript. All authors read and approved the final manuscript. 
Acknowledgement: The authors gratefully acknowledge the authority of the councilor office and union parishad for providing useful information about our subjects. Also thanks to all participants for giving their information.

Author details: Department of Statistics, University of Rajshahi, Rajshahi 6205, Bangladesh.

\section{References}

1. Al Ghwass A, Mohamed M, Dalia A. Prevalence and predictors of 6-month exclusive breastfeeding in a rural area in Egypt. Breastfeed Med. 2011; 6: 191-196.

2. Al Ketbi MI, Al Noman S, Al Ali A, Darwish E, Al Fahim M, Rajah J. Knowledge, attitudes, and practices of breastfeeding among women visiting primary healthcare clinics on the island of Abu Dhabi, United Arab Emirates. Int Breastfeed J. 2018; 13:26. doi: 10.1186/s13006-018-0165-x.

3. Alamirew MW, Bayu NH, Birhan Tebeje N, Kassa SF. Knowledge and Attitude towards Exclusive Breast Feeding among Mothers Attending Antenatal and Immunization Clinic at Dabat Health Center, Northwest Ethiopia: A Cross-Sectional Institution Based Study. Nurs Res Pract. 2017; 2017:6561028. doi: 10.1155/2017/6561028.

4. Aliyu AM, Shehu M. Knowledge, Attitude and Practice of Exclusive Breastfeeding among Multigravid Women Attending Antenatal Clinic in Aminu Kano Teaching Hospital. IOSR-JNHS. 2016; 5(6):59-74.

5. Al-Kohji S, Said HA, Selim NA. Breastfeeding practice and determinants among Arab mothers in Qatar. Saudi Med J. 2012; 33(4):436-443.

6. Alzaheb RA. A Review of the Factors Associated With the Timely Initiation of Breastfeeding and Exclusive Breastfeeding in the Middle East. Clin Med Insights Pediatr. 2017; 11:1179556517748912. doi: $10.1177 / 1179556517748912$.

7. Amin TT, Abdulrahman AG, Muhaidib NSA, Hamdan OAA. Breastfeeding attitudes and knowledge among future female physicians and teachers in Saudi Arabia. Health Sci J. 2014; 8(1):102-115.

8. Arage G, Gedamu H. Exclusive Breastfeeding Practice and Its Associated Factors among Mothers of Infants Less Than Six Months of Age in Debre Tabor Town, Northwest Ethiopia: A Cross-Sectional Study. Ad Public Health. http://dx.doi.org/10.1155/2016/3426249.

9. United Nations Children's Fund (UNICEF), Child info: Monitoring the situation of children and women. Statistics by area: Child protection. New York; 2014

10. Asare BY, Preko JV, Baafi D, Dwumfour-Asare B. Breastfeeding practices and determinants of exclusive breastfeeding in a cross-sectional study at a child welfare clinic in Tema Manhean, Ghana. Int Breastfeed J. 2018; 13 (12). doi: 10.1186/s13006-018-0156-y.

11. Asfaw MM, Argaw MD, Kefene ZK. Factors associated with exclusive breastfeeding practices in Debre Berhan District, Central Ethiopia: a cross sectional community based study. Int Breastfeed J. 2015; 10:23.doi: 10.1186/s13006-015-0049-2.

12. Ayed AAN. Knowledge, attitude, and practice regarding exclusive breastfeeding among mothers attending primary health care centers ABHA CITY. Int J Med Sci Public Health. 2014; 3(11): 1355- 
1363.

13. Boccolini CS, Carvalho MLD, Oliveira MICD (2015). Factors associated with exclusive breastfeeding in the first six months of life in Brazil: a systematic review. Rev Saúde Pública. 2015; 49:91. doi:10.1590/S0034-8910.

14. Camp WG. Formulating and Evaluating Theoretical Frameworks for Career and Technical Education Research. J Voca Educa Res. 2001; 26 (1): 27-39.

15. Dwinanda N, Syarif BH, Sjarif DR. Factors affecting exclusive breastfeeding in term infants. Paediatr Indones. 2018; 58 (1):25-35.

16. González-Pascual1 JL, Aguilar-Ortega JM, Esteban-Gonzalo L et al. Comparison of attitudes to breastfeeding among Spanish-born and Chinese-born postpartum women in Madrid. Int Breastfeed J. 2018; 13: 45. doi: 10.1186/s13006-018-0187-4.

17. Haghighi M, Taheri E. Factors associated with breastfeeding in the first hour after birth, in baby friendly hospitals, Shiraz-Iran. Int J Pediatr. 2015; 3(51): 889-896.

18. National Institute of Population Research and Training (NIPORT), Mitra and Associates, and ICF International. Bangladesh Demographic and Health Survey 2014: Dhaka, Bangladesh, and Rockville, Maryland, Mitra and Associates, and ICF International.

19. Islam MA, Mamun ASMA, Hossain MM, Bharati P, Saw A, Lestrel PE, et al. Prevalence and factors associated with early initiation of breastfeeding among Bangladeshi mothers: A nationwide crosssectional study. PLoS One. 2019; 14(4):e0215733. doi: 10.1371/journal.pone.0215733.

20. Climate Change Cell (CCC). Climate Change and Health Impacts in Bangladesh. Climate Change Cell, DoE, MoEF; Component 4b, CDMP, MoFDM. 2009, Dhaka.

21. Mahbubar Rahman, Md. Rajshahi District. In Islam, Sirajul; Jamal, Ahmed A. (eds.). Banglapedia: National Encyclopedia of Bangladesh(Second ed.). Asiatic Society of Bangladesh. 2012.

22. Cochran WG. Sampling Techniques. 1963; 2nd Ed., New York: John Wiley and Sons, Inc.

23. Martin, R. \& Saller, K. Lehrbuch der anthropologie. 1957. Gustav Fischer Verlag, Stuttgart.

24. Pamarthi K, Palli JK. Factors influencing early initiation of breast feeding among mothers in North Coastal Andhra Pradesh, India. Int J Community Med Public Health. 2019; 6:4316-21.

25. Borah M, Baruah J, Baruah R, Baruah M. Prevalence and factors affecting early initiation of breastfeeding in rural areas of Dibrugarh district, Assam. Int J Community Med Public Health. 2019; 6:2176-81.

26. Chan YH. Biostatistics 202: logistic regression analysis. Singapore Med J. 2004; 45(4):149-53.

27. The DHS Program. Bangladesh: DHS 2017-18 - Key Indicators Report. 2019. https://dhsprogram.com/pubs/pdf/PR104/PR104.

28. Phukan D, Ranjan M, Dwivedi LK. Impact of timing of breastfeeding initiation on neonatal mortality in India. Int Breastfeed J. 2018;13:27.doi: 10.1186/s13006-018-0162-0.

29. Hanif HM. Trends in breastfeeding and complementary feeding practices in Pakistan, 1990-2007. Int Breastfeed J. 2011; 6: 15. doi: 10.1186/1746-4358-6-15. 
30. Berde AS, Yalcin SS. Determinants of early initiation of breastfeeding in Nigeria: a population-based study using the 2013 demographic and health survey data. BMC Pregnancy Child birth. 2016; 16(32). doi: 10.1186/s12884-016-0818-y.

31. Zarshenas M, Zhao Y, Binns CW, Scott JA. Determinants of in-hospital feeding practices in Shiraz, Iran: Results of a prospective cohort study. 2019; 46(1):137-145.

32. Tongun JB, Sebit MB, Mukunya D, Ndeezi G, Nankabirwa V, Tylleskar T, et al. Factors associated with delayed initiation of breastfeeding: a cross-sectional study in South Sudan. Int Breastfeed J. 2018; 13:28. https://doi.org/10.1186/s13006-018-0170-0.

33. Beyene MG, Geda NR, Habtewold TD, Assen ZM. Early initiation of breastfeeding among mothers of children under the age of 24 months in Southern Ethiopia. Int Breastfeed J. 2016; 12 (1). doi: 10.1186/s13006-016-0096-3.

34. Wu Y, Wang Y, Huang J, Zhang Z, Wang J, Zhou L. The association between caesarean delivery and the initiation and duration of breastfeeding: a prospective cohort study in China. European Journal of Clinical Nutrition. 2018; 72:1644-1654. https://doi.org/10.1038/s41430-018-0127-9.

35. Hossain, M., Islam, A., Kamarul, T. et al.Exclusive breastfeeding practice during first six months of an infant's life in Bangladesh: a country based cross-sectional study. BMC Pediatr 18, 93 (2018). https://doi.org/10.1186/s12887-018-1076-0

36. Kiani SN, Rich KM, Herkert D, Safon C, Pérez-Escamilla R. Delivery mode and breastfeeding outcomes among new mothers in Nicaragua. Maternal and child nutrition. 2018; 14(1):e12474. https://doi.org/10.1111/mcn.12474.

37. Krause KM, Lovelady CA, Østbye T. Predictors of Breastfeeding in Overweight and Obese Women: Data From Active Mothers Postpartum (AMP). Matern Child Health J. 2011; 15(3):367- doi: 10.1007/s10995-010-0667-7.

38. Liu J, Smith MG, Dobre MA, Ferguson JE. (2010). Maternal obesity and breast-feeding practices among white and black women. Obesity. 2010; 18:175-182.

39. Baker JL, Michaelsen KF, Sørensen TI, Rasmussen KM. High prepregnant body mass index is associated with early termination of full and any breastfeeding in Danish women. Am J Clin Nutr. 2007; 86: 404-411.

40. Takahashi K, Ganchimeg T, Ota E, Vogel JP, Souza JP, Laopaiboon M, et al. Prevalence of early initiation of breastfeeding and determinants of delayed initiation of breastfeeding: secondary analysis of the WHO Global Survey. Sci Rep. 2017; 7:44868. doi:10.1038/srep44868.

41. Radwan H. Patterns and determinants of breastfeeding and complementary feeding practices of Emirati mothers in the United Arab Emirates. BMC Public Health. 2013; 13: 171.

42. Sharma A, Thakur PS, Tiwari R, Kasar PK, Sharma R, Kabirpanthi V. Factors associated with early initiation of breastfeeding among mothers of tribal area of Madhya Pradesh, India: a community based cross sectional study. Int J Community Med Public Heal. 2016; 3: 194-9.

43. Hassan AA, Taha Z, Ahmed MAA, Ali AAA, Adam I. Assessment of initiation of breastfeeding practice in Kassala, Eastern Sudan: a community-based study. International Breastfeeding Journal. 2018; 13: 
34. https://doi.org/10.1186/s13006-018-0177-6.

44. Yu Z, Han S, Zhu J, Sun X, Ji C, Guo X. Pre-Pregnancy Body Mass Index in Relation to Infant Birth Weight and Offspring Overweight/Obesity: A Systematic Review and Meta-Analysis. PLoS One. 2013; 8(4):e61627. doi: 10.1371/journal.pone.0061627.

\section{Tables}

Table 1: Independent variables, their categories and codes

\begin{tabular}{|c|c|c|c|c|c|}
\hline Variable & Category & Code & Variable & Category & Code \\
\hline Mode of delivery & Caesarean & 1 & $\begin{array}{l}\text { Husbands' } \\
\text { education level }\end{array}$ & $\begin{array}{l}\text { Uneducated or } \\
\text { primary }\end{array}$ & 1 \\
\hline & Vaginal & 2 & & Secondary & 2 \\
\hline \multirow[t]{2}{*}{ Place of delivery } & Home & 1 & & Higher & 3 \\
\hline & Public & 2 & $\begin{array}{l}\text { Age at first birth } \\
\text { (year) }\end{array}$ & $<20$ & 1 \\
\hline \multirow{3}{*}{$\begin{array}{l}\text { Monthly family } \\
\text { income (Taka) }\end{array}$} & $\begin{array}{l}\text { Private } \\
<15000\end{array}$ & $\frac{3}{1}$ & Mothers' & $\begin{array}{l}\geq 20 \\
\text { Under nutrition }\end{array}$ & $\frac{2}{1}$ \\
\hline & & & $\begin{array}{l}\text { nutritional } \\
\text { status }\end{array}$ & & \\
\hline & $15000-25000$ & 2 & & $\begin{array}{l}\text { Healthy } \\
\text { (normal } \\
\text { weight) }\end{array}$ & 2 \\
\hline \multirow{4}{*}{$\begin{array}{l}\text { Mothers' education } \\
\text { level }\end{array}$} & $>25000$ & $\frac{3}{1}$ & Tvne of family & Over nutrition & 3 \\
\hline & primary & & & & \\
\hline & $\begin{array}{l}\text { Secondary } \\
\text { Higher }\end{array}$ & $\frac{2}{3}$ & & Joint & 2 \\
\hline & Higner & & residence & Uroan & \\
\hline \multirow{5}{*}{$\begin{array}{l}\text { Mothers' age } \\
\text { (year) }\end{array}$} & $15-19$ & 1 & & Rural & 2 \\
\hline & $20-24$ & 2 & Gender of & Boy & 1 \\
\hline & $25-29$ & 3 & & Girl & 2 \\
\hline & $30-34$ & 4 & & & \\
\hline & 35 and above & 5 & & & \\
\hline
\end{tabular}

Table 2: Association between early initial breastfeeding and socio-economic, demographic and anthropometric factors 


\begin{tabular}{|c|c|c|c|c|c|}
\hline \multirow[b]{2}{*}{ Variable } & \multirow[b]{2}{*}{ Group, N(\%) } & \multicolumn{2}{|c|}{$\begin{array}{c}\text { Early initiation of } \\
\text { breastfeeding status }\end{array}$} & \multirow[b]{2}{*}{$\begin{array}{l}\text { Chi- } \\
\text { square/ } \\
\text { Fisher's } \\
\text { exact } \\
\text { value }\end{array}$} & \multirow[b]{2}{*}{ p-value } \\
\hline & & No $\left(\frac{11.60 \%}{\mathbf{N}(\%)_{-}}\right)$ & $\begin{array}{l}\text { Yes } \\
(88.40 \%), \\
\mathrm{N}(\%)\end{array}$ & & \\
\hline \multirow{2}{*}{$\begin{array}{l}\text { Mode of } \\
\text { delivery }\end{array}$} & Cesarean, 177(42) & $33(18.6)$ & $144(81.4)$ & 14.572 & $\mathrm{p}<0.001$ \\
\hline & Vaginal, 244(58) & $16(6.6)$ & $228(93.4)$ & & \\
\hline \multirow[t]{3}{*}{$\begin{array}{l}\text { Place of } \\
\text { delivery }\end{array}$} & Home, $45(10.7)$ & $1(2.2)$ & $44(97.8)$ & 31.936 & $\mathrm{p}<0.001$ \\
\hline & Public, 200(47.5) & $9(4.5)$ & 191(95.5) & & \\
\hline & Private, $176(41.8)$ & $39(22.2)$ & $137(77.8)$ & & \\
\hline \multirow[t]{3}{*}{$\begin{array}{l}\text { Monthly family } \\
\text { income (Taka) }\end{array}$} & $<15000,287(68.2)$ & $6(2.1)$ & $280(97.9)$ & 85.918 & $\mathrm{p}<0.001$ \\
\hline & $\begin{array}{l}15000-25000 \\
58(13.8)\end{array}$ & $14(24.1)$ & $44(75.9)$ & & \\
\hline & $>25000,76(18.0)$ & $29(38.2)$ & $47(61.8)$ & & \\
\hline \multirow[t]{3}{*}{$\begin{array}{l}\text { Mothers' } \\
\text { education level }\end{array}$} & $\begin{array}{l}\text { Uneducated or } \\
\text { primary, 201(47.7) }\end{array}$ & $10(5.0)$ & 191(95.0) & 25.061 & $\mathrm{p}<0.001$ \\
\hline & $\begin{array}{l}\text { Secondary, } \\
173(41.1)\end{array}$ & $25(14.5)$ & $148(85.5)$ & & \\
\hline & Higher, $47(11.2)$ & $14(29.8)$ & $33(70.2)$ & & \\
\hline \multirow[t]{3}{*}{$\begin{array}{l}\text { Husbands' } \\
\text { education level }\end{array}$} & $\begin{array}{l}\text { Uneducated or } \\
\text { primary, } 200(47.5)\end{array}$ & $8(4.0)$ & $192(96.0)$ & 61.333 & $\mathrm{p}<0.001$ \\
\hline & $\begin{array}{l}\text { Secondary, } \\
159(37.8)\end{array}$ & $16(10.1)$ & $143(89.9)$ & & \\
\hline & Higher, 62(14.7) & $25(40.3)$ & $37(59.7)$ & & \\
\hline \multirow[t]{2}{*}{$\begin{array}{l}\text { Age at first birth } \\
\text { (year) }\end{array}$} & $<20,199(47.3)$ & $14(7.0)$ & $185(93.0)$ & 7.777 & 0.005 \\
\hline & $\geq 20,222(52.7)$ & $35(15.8)$ & $187(84.2)$ & & \\
\hline \multirow[t]{3}{*}{$\begin{array}{l}\text { Mothers' } \\
\text { nutritional } \\
\text { status }\end{array}$} & $\begin{array}{l}\text { Under nutrition, } \\
08(25.7)\end{array}$ & $1(0.9)$ & $107(99.1)$ & 28.629 & $\mathrm{p}<0.001$ \\
\hline & Healthy, 85(67.7) & $38(13.3)$ & $247(86.7)$ & & \\
\hline & $\begin{array}{l}\text { Over nutrition, } \\
28(6.6)\end{array}$ & $10(35.7)$ & $18(64.3)$ & & \\
\hline \multirow[t]{2}{*}{ Type of family } & $\begin{array}{l}\text { Nuclear, } \\
346(82.19)\end{array}$ & $36(10.4)$ & $310(89.6)$ & 2.877 & 0.090 \\
\hline & Joint, $75(17.81)$ & $13(17.3)$ & $62(82.7)$ & & \\
\hline \multirow[t]{2}{*}{$\begin{array}{l}\text { Type of } \\
\text { residence }\end{array}$} & Urban, 122(28.98) & $49(40.2)$ & $73(59.8)$ & 135.908 & $\mathrm{p}<0.001$ \\
\hline & Rural, 299(71.02) & $0(0)$ & $299(100)$ & & \\
\hline \multirow[t]{5}{*}{$\begin{array}{l}\text { Mothers' age } \\
\text { (year) }\end{array}$} & $15-19,17(4.04)$ & $9(52.9)$ & $8(47.1)$ & 42.936 & $\mathrm{p}<0.001$ \\
\hline & $20-24,181(42.99)$ & $11(6.1)$ & $170(93.9)$ & & \\
\hline & $25-29,153(36.34)$ & $20(13.1)$ & $133(86.9)$ & & \\
\hline & $30-34,51(12.11)$ & $3(5.9)$ & $48(94.1)$ & & \\
\hline & $\begin{array}{l}35 \text { and above, } \\
19(4.52)\end{array}$ & $6(31.6)$ & $13(68.4)$ & & \\
\hline $\begin{array}{l}\text { Gender of } \\
\text { children }\end{array}$ & Boy, 212(50.36) & $21(9.9)$ & $191(90.1)$ & 1.248 & 0.264 \\
\hline
\end{tabular}




\begin{tabular}{|c|c|c|c|c|c|}
\hline \multirow{3}{*}{$\begin{array}{l}\text { Mothers' } \\
\text { occupation }\end{array}$} & Girl, 209(49.64) & $28(13.4)$ & 181(86.6) & & \\
\hline & $\begin{array}{l}\text { House wife, } \\
415(98.57)\end{array}$ & $46(11.1)$ & $369(88.9)$ & 8.709 & 0.023 \\
\hline & Others, $6(1.43)$ & $3(50.0)$ & $3(50.0)$ & & \\
\hline \multirow[t]{2}{*}{$\begin{array}{l}\text { Husbands' } \\
\text { occupation }\end{array}$} & $\begin{array}{l}\text { Farmer, } \\
235(55.82)\end{array}$ & $5(2.1)$ & $230(97.9)$ & 46.789 & $\mathrm{p}<0.001$ \\
\hline & Others, $186(44.18)$ & $44(23.7)$ & $142(76.3)$ & & \\
\hline \multirow{2}{*}{$\begin{array}{l}\text { Number of } \\
\text { children }\end{array}$} & One, $233(55.34)$ & $22(9.4)$ & $211(90.6)$ & 2.449 & 0.118 \\
\hline & $\begin{array}{l}\text { More than one, } \\
188(44.66)\end{array}$ & $27(14.4)$ & 161(85.6) & & \\
\hline \multirow{2}{*}{$\begin{array}{l}\text { Planning of } \\
\text { conception }\end{array}$} & Yes, $352(83.60)$ & $37(10.5)$ & $315(89.5)$ & 2.655 & 0.103 \\
\hline & No, $69(16.40)$ & $12(17.4)$ & $57(82.6)$ & & \\
\hline \multirow{2}{*}{$\begin{array}{l}\text { Taking advice } \\
\text { during } \\
\text { pregnancy }\end{array}$} & Yes, 399 (94.77) & $39(9.8)$ & $360(90.2)$ & 25.810 & $\mathrm{p}<0.0001$ \\
\hline & No, 22(5.23) & $10(45.5)$ & $12(54.5)$ & & \\
\hline
\end{tabular}

Table 3: Effect of socio-economic and demographic factors on initial breastfeeding among mothers in Rajshahi district, Bangladesh 


\begin{tabular}{|c|c|c|c|c|c|c|c|}
\hline Variable with groups & B & SE & Wald & p-value & AOR & $\begin{array}{l}95 \% \\
\text { AOR } \\
\text { Lower }\end{array}$ & $\begin{array}{l}\text { CI for } \\
\text { Upper }\end{array}$ \\
\hline $\begin{array}{l}\text { Mode of delivery (Caesarean Vs } \\
\text { Vaginal }^{R} \text { ) }\end{array}$ & -1.183 & 0.323 & 13.450 & 0.001 & 0.306 & 0.163 & 0.576 \\
\hline Place of delivery & & & 10.031 & $\begin{array}{l}0.007 \\
0.363\end{array}$ & & & \\
\hline $\begin{array}{l}\text { Public Hospital Vs Home }{ }^{\mathrm{R}} \\
\text { Private Hosnital Vs Home }\end{array}$ & $\begin{array}{l}-1.024 \\
-2.405\end{array}$ & $\begin{array}{l}1.126 \\
1.109\end{array}$ & 0.827 & $\begin{array}{l}0.363 \\
0.030\end{array}$ & $\begin{array}{l}0.359 \\
0.090\end{array}$ & $\begin{array}{l}0.040 \\
0.010\end{array}$ & $\begin{array}{l}3.263 \\
0.794\end{array}$ \\
\hline $\begin{array}{l}\text { Private Hospital Vs Home }{ }^{R} \\
\text { Monthly family income (Taka) }\end{array}$ & -2.405 & 1.109 & 16.443 & 0.000 & & & \\
\hline $15000-25000 \mathrm{Vs} \leq 15000^{\mathrm{R}}$ & -2.330 & 0.600 & 15.074 & 0.000 & 0.097 & 0.030 & 0.315 \\
\hline$\geq 25000 \mathrm{Vs} \leq 15000^{\mathrm{R}}$ & -2.042 & 0.620 & 10.864 & 0.001 & 0.130 & 0.039 & 0.437 \\
\hline $\begin{array}{l}\text { Husbands' education level } \\
\text { Secondary Vs Primary or }\end{array}$ & -0.463 & 0.669 & $\begin{array}{l}6.323 \\
0.480\end{array}$ & $\begin{array}{l}0.042 \\
0.489\end{array}$ & 0.629 & 0.170 & 2.335 \\
\hline $\begin{array}{l}\text { Vs Primary or } \\
\text { Cated }^{\mathrm{R}}\end{array}$ & -1.792 & 0.796 & 5.074 & 0.024 & 0.167 & 0.035 & 0.792 \\
\hline Moth & -0.031 & 0.625 & $\begin{array}{l}4.474 \\
0.003\end{array}$ & $\begin{array}{l}0.107 \\
0.960\end{array}$ & 0.969 & 0.285 & 3.296 \\
\hline 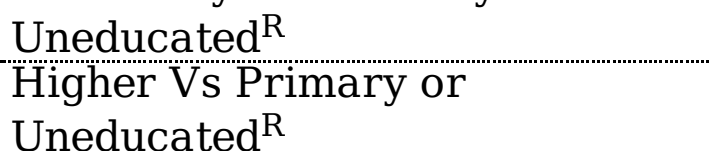 & 1.297 & 0.812 & 2.548 & 0.110 & 3.658 & 0.744 & 17.981 \\
\hline at first birth & 0.262 & 0.448 & 0.341 & 0.559 & 1.299 & 0.540 & 3.125 \\
\hline Mothe & & & $\begin{array}{l}5.208 \\
4.383\end{array}$ & $\begin{array}{l}0.074 \\
0.036\end{array}$ & & & \\
\hline $\begin{array}{l}\text { Healthy Vs Under nutrition } \\
\text { Over nutrition Vs Under } \\
\text { nutrition }{ }^{\mathrm{R}}\end{array}$ & $\begin{array}{l}-2.227 \\
-2.630\end{array}$ & $\begin{array}{l}1.064 \\
1.154\end{array}$ & $\begin{array}{l}4.383 \\
5.193\end{array}$ & $\begin{array}{l}0.036 \\
0.023\end{array}$ & $\begin{array}{l}0.108 \\
0.072\end{array}$ & & $\begin{array}{l}0.867 \\
0.692\end{array}$ \\
\hline Mothers' age (year) & & & 31.742 & $\mathrm{p}<0.001$ & & & \\
\hline $15-19$ Vs 35 and above ${ }^{\mathrm{R}}$ & -0.891 & 0.693 & 1.655 & 0.198 & 0.410 & 0.106 & 1.594 \\
\hline $20-24$ Vs 35 and above ${ }^{R}$ & 1.965 & 0.583 & 11.341 & $p<0.001$ & 7.133 & 2.273 & 22.381 \\
\hline 25-29 Vs 35 and above ${ }^{\mathrm{R}}$ & 1.121 & 0.549 & 4.177 & 0.041 & 3.069 & 1.047 & 8.997 \\
\hline 30-34 Vs 35 and above ${ }^{\mathrm{R}}$ & 1.999 & 0.773 & 6.688 & 0.010 & 7.385 & 1.623 & 33.607 \\
\hline $\begin{array}{l}\text { Mothers' occupation, } \\
\text { (House wife Vs Others }{ }^{\mathrm{R}} \text { ) }\end{array}$ & 1.221 & .836 & 2.135 & 0.144 & 3.390 & 0.659 & 17.438 \\
\hline $\begin{array}{l}\text { Husbands' occupation, } \\
\text { Farmer Vs Others }{ }^{\mathrm{R}}\end{array}$ & 2.608 & 0.486 & 28.823 & $p<0.001$ & 13.568 & 5.237 & 35.154 \\
\hline $\begin{array}{l}\text { Planning concept, } \\
\text { Yes Vs No }\end{array}$ & 1.782 & 0.498 & 12.780 & $\mathrm{p}<0.001$ & 5.941 & 2.237 & 15.780 \\
\hline $\begin{array}{l}\text { Taking advice, } \\
\text { Yes Vs No }\end{array}$ & 2.015 & 0.489 & 16.986 & $p<0.001$ & 7.502 & 2.877 & 19.559 \\
\hline Constant & 7.601 & 1.548 & 24.110 & $p<0.001$ & 2000.883 & & \\
\hline
\end{tabular}

Nagelkerke $\mathbf{R}^{2}$ - value $=0.566$

Hosmer and Lemeshow Test

Chi-sauare value $=5.568$ p-value $=0.696$

N.B: R=Reference Category, $\mathrm{B}=$ Co-efficient, $\mathrm{SE}=$ Standard Error, $\mathrm{AOR}=$ Adjusted Odds ratio, $\mathrm{CI}=$ Confidence Interval.

Figures 


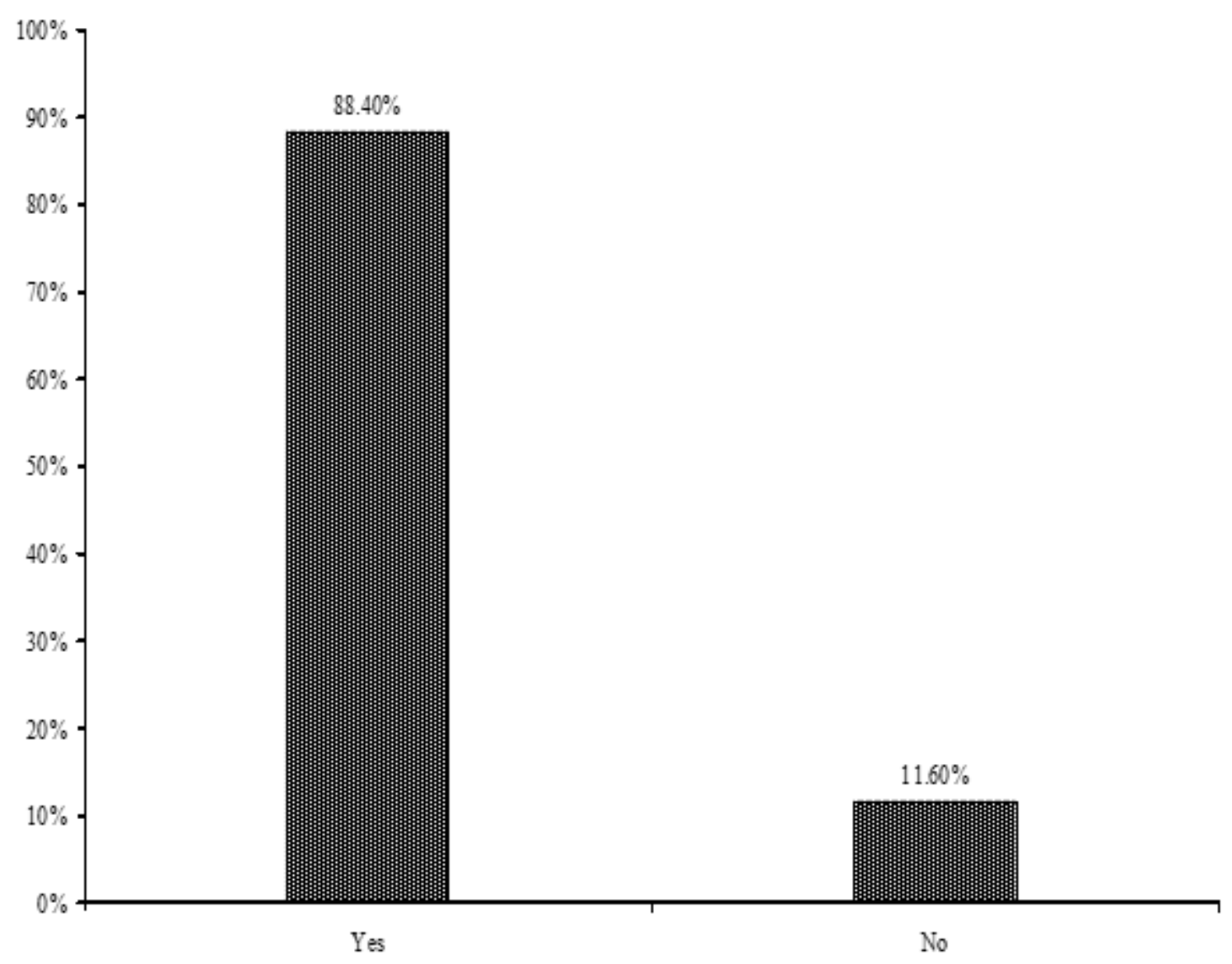

Figure 1

Prevalence of initial breastfeeding among mothers in Rajshahi district, Bangladesh

\section{Supplementary Files}

This is a list of supplementary files associated with this preprint. Click to download.

- SupplementaryFile.doc

- MethodswithEquations.docx 